University of Nebraska - Lincoln

DigitalCommons@University of Nebraska - Lincoln

\title{
Modeling weather and stocking rate effects on forage and steer production in northern mixed-grass prairie
}

\author{
Q. X. Fang \\ Qingdao Agricultural University
}

A. A. Andales

Colorado State University, Allan.Andales@colostate.edu

J. D. Derner

USDA-ARS, High Plains Grasslands Research Station, Justin.Derner@ars.usda.gov

L. R. Ahuja

USDA-ARS, Agricultural Systems Research Unit

L. Ma

USDA-ARS, Agricultural Systems Research Unit

See next page for additional authors

Follow this and additional works at: https://digitalcommons.unl.edu/usdaarsfacpub

Fang, Q. X.; Andales, A. A.; Derner, J. D.; Ahuja, L. R.; Ma, L.; Bartling, P. N. S.; Reeves, J. L.; and Qi, Z., "Modeling weather and stocking rate effects on forage and steer production in northern mixed-grass prairie" (2014). Publications from USDA-ARS / UNL Faculty. 1461.

https://digitalcommons.unl.edu/usdaarsfacpub/1461

This Article is brought to you for free and open access by the U.S. Department of Agriculture: Agricultural Research Service, Lincoln, Nebraska at DigitalCommons@University of Nebraska - Lincoln. It has been accepted for inclusion in Publications from USDA-ARS / UNL Faculty by an authorized administrator of DigitalCommons@University of Nebraska - Lincoln. 


\section{Authors}

Q. X. Fang, A. A. Andales, J. D. Derner, L. R. Ahuja, L. Ma, P. N. S. Bartling, J. L. Reeves, and Z. Qi 


\title{
Modeling weather and stocking rate effects on forage and steer production in northern mixed-grass prairie
}

\author{
Q.X. Fang ${ }^{\text {a }}$, A.A. Andales ${ }^{\text {b,* }}$, J.D. Derner ${ }^{c}$, L.R. Ahuja ${ }^{\mathrm{d}}$, L. Ma ${ }^{\mathrm{d}}$, P.N.S. Bartling ${ }^{\mathrm{d}}$, J.L. Reeves ${ }^{\mathrm{c}}$, Z. $\mathrm{Qi}^{\mathrm{e}}$ \\ a Qingdao Agricultural University, Qingdao 266109, China \\ ${ }^{\mathrm{b}}$ Department of Soil and Crop Sciences, Colorado State University, 1170 Campus Delivery, Fort Collins, CO 80523-1170, USA \\ c USDA-ARS, High Plains Grasslands Research Station, 8408 Hildreth Road, Cheyenne, WY 82009-8899, USA \\ ${ }^{\mathrm{d}}$ USDA-ARS, Agricultural Systems Research Unit, Fort Collins, CO 80526, USA \\ ${ }^{\mathrm{e}}$ Department of Bioresource Engineering, McGill University, QC, Canada
}

\section{A R T I C L E I N F O}

\section{Article history:}

Received 10 January 2014

Received in revised form 18 May 2014

Accepted 22 May 2014

Available online 14 June 2014

\section{Keywords:}

GPFARM-Range

Rangeland model

Peak standing crop

Steer

\begin{abstract}
A B S T R A C T
Stocking rate (SR) is the primary management factor that influences livestock gains, plant community changes and forage production, as well as economic returns for livestock producers. More effective stocking decision making by ranchers in the semi-arid northern mixed-grass prairie requires clearly understanding forage production and yearling steer weight gain (SWG) responses to SR and high weather variability. The objectives of this study were to: (1) test the Great Plains Framework for Agricultural Resource Management-Range (GPFARM-Range) model for predicting forage production and SWG under three experimental SR treatments and long-term weather conditions on semiarid northern mixed-grass prairie in southeast Wyoming, USA; and (2) quantify the threshold responses of forage production and SWG to SR and the yearly weather variability across years using long-term simulations with SR higher than those experimentally evaluated. We improved upon the GPFARM-Range model to simulate peak standing crop (PSC) and SWG for three experimental SR treatments (low, moderate and high; 0.20, 0.33 and 0.44 steer ha $^{-1}$, respectively) from 1982 to 2012 at Cheyenne, Wyoming, USA. The improved model accurately predicted the effects of SR on PSC and SWG across years (root mean square errors from 355 to $387 \mathrm{~kg} \mathrm{ha}^{-1}$ for PSC and from 12.8 to $14.2 \mathrm{~kg} \mathrm{head}^{-1}$ for SWG). We ran the model with long-term weather data and $50-300 \%$ higher SR (0.66-1.76 steer ha $\left.{ }^{-1}\right)$ than the high SR experimental treatment. Differential responses of predicted total intake of digestible nutrients (quadratic increase) and metabolic maintenance (linear increase) to these higher SR resulted in a quadratic increase of predicted SWG with SR and high yearly variability at high SR levels. The financially-optimum SR with highest profits was reduced to 0.33 steer ha $^{-1}$ for dry or normal seasons and 0.44 steer ha ${ }^{-1}$ for wet seasons. Such reduced SR can also benefit land conservation with high PSC and low harvest efficiency. The moderate SR with $25 \%$ harvest efficiency was determined between 0.22 and 0.33 steer ha ${ }^{-1}$ for dry or normal seasons, or between 0.33 and 0.44 steer ha $^{-1}$ for wet seasons. These results provide useful direction for selecting an effective SR to achieve high economic net return with lower yearly variability (risk) and reduced likelihood of rangeland degradation.
\end{abstract}

(c) 2014 Elsevier Ltd. All rights reserved.

\section{Introduction}

Seasonal weather variation and stocking rate (number of animals per unit land area for the grazing season, SR) influence forage production (Biondini et al., 1998; Derner and Hart, 2007), cattle weight gain (Derner et al., 2008b; Reeves et al., 2013a,b, 2014), and the economic net returns (Hart et al., 1988; Manley et al., 1997) in semiarid rangelands. For example, forage production

\footnotetext{
* Corresponding author. Tel.: +1970 4916516.

E-mail address: Allan.Andales@colostate.edu (A.A. Andales).
}

and livestock weight gain responses to SR differ between drought and wet conditions (Gillen and Sims, 2006), across locations and climates (Smart et al., 2010), and with different plant communities (Derner and Hart, 2007; Patton et al., 2007; Reeves et al., 2014).

Greater spring precipitation (Derner et al., 2008b; Reeves et al., 2013ab, 2014), as well as cool springs (Reeves et al. 2013a, 2014) can increase livestock weight gains in northern mixed-grass prairie. Additionally, livestock weight gains were more sensitive to seasonal weather influences as SR increased (Reeves et al., 2013b, 2014). These results can be used by land managers to adjust SR levels to seasonal weather variability. However, clearly understanding 
the SR effect on the variability of forage production or livestock weight gain due to weather variations is needed to better match cattle forage demand to forage availability across seasons and reduce enterprise risk and land degradations.

Field studies have generally evaluated only a few SR levels due to limitations in experimental design (i.e., adequate replication and logistical difficulties associated with grazing studies) and concerns about poor animal performance when SR levels are high. However, system models provide the ability to extend field experimental results by simulating effects of various SR on forage production and livestock weight gain for various weather conditions. Furthermore, system models could explore the threshold effect of SR on forage production and livestock weight gains across a wide range of weather conditions, which can assist in stocking decisions by ranchers.

Many process-based models have been developed to simulate forage growth and livestock production, such as GRAZPLAN (Freer et al., 1997) and AgMod (Johnson, 2013) in Australia, and the Farm Assessment Tool (FASSET, Berntsen et al., 2003) in Denmark. These models were mainly developed for the local conditions, such as pasture species, and grazing and fertilizer management options (Snow et al., 2014). In the Northern Great Plains of U.S., the Great Plains Framework for Agricultural Resource Management-Range (GPFARM-Range) model was developed by USDA-Agricultural Research Service to address simultaneous influences of weather, soils, and various SR levels on forage production and livestock weight gains in rangelands (Andales et al., 2005) and was applied for the semiarid rangeland systems in the region (Qi et al., 2012).

The GPFARM-Range model, using the Natural Resources Conservation Service (NRCS) recommended moderate SR, has been evaluated for forage production (Andales et al., 2005, 2006) and cow-calf weight gains (Andales et al., 2005), as well as soil carbon storage (Qi et al., 2012) in semiarid rangelands of North America. However, the model has not been evaluated for simulating longterm forage production and livestock weight gains for SR levels less than or greater than the moderate SR. Moreover, using the model to extend responses of forage production and livestock weight gains to SR greater than those previously experimentally evaluated can provide valuable information for land managers. For example, models could be used to determine the biophysical optimum SR for both forage production and livestock weight gains. To increase the value of GPFARM-Range model for land managers, the first objective of this study was to test the model for predicting forage production and livestock weight gains under three experimental SR treatments (low, moderate and high; see below) and long-term weather conditions on semiarid northern mixed-grass prairie in southeast Wyoming, USA. Our second objective was to quantify the threshold responses of forage production and livestock weight gains to SR and the yearly weather variability across years using long-term simulations with SR higher than those experimentally evaluated.

\section{Materials and methods}

\subsection{Site description and field experiments}

Experimental data used for model calibration and evaluation were from a long-term (31 yr) grazing experiment on semiarid northern mixed-grass prairie at the High Plains Grasslands Research Station (HPGRS) in Cheyenne, Wyoming, USA. $\left(41^{\circ} 11^{\prime} \mathrm{N}\right.$, 104²3'W) (Hart et al., 1988; Manley et al., 1997; Derner and Hart, 2007; Derner et al., 2008b; Reeves et al., 2013b). Mean annual precipitation at the site is $381 \mathrm{~mm}$ with a peak in May and June. The soils are medium textured and well drained, dominated by
Albinas (fine-loamy, mixed, superactive, mesic pachic argiustolls) loam, with other soils including Altvan (fine-loamy over sandy or sandy-skeletal, mixed, superactive, mesic aridic argiustolls), and Ascalon (fine-loamy, mixed, superactive, mesic aridic agriustolls) loams (Stevenson et al., 1984).

Season-long (June-October), continuous grazing treatments were initiated in 1982 with three SR levels of low ( 8 steers/40 ha ( 0.2 steer $\mathrm{ha}^{-1}$ ), about $35 \%$ below Natural Resources Conservation Service (NRCS)-recommended rate), moderate (8 steers/24 ha ( 0.33 steer ha $\left.{ }^{-1}\right)$, the NRCS-recommended rate) and high ( 8 steers/ 18 ha $\left(0.44\right.$ steer ha $\left.{ }^{-1}\right), 33 \%$ greater than the NRCS-recommended rate; Hart et al., 1988). The moderate SR level (or similar) was most commonly practiced by the local ranchers in the region. Treatments were established using a randomized block design with two replicates (except for the low SR treatment without replicate) on a study area that had previously been grazed very lightly by livestock and wildlife (Hart et al., 1988). Yearling steers were used as grazing animals and each steer was weighed before and after the grazing season. All experimental procedures were performed according to HPGRS Animal Care and Use Committee oversight. Cattle did not graze pastures in 1989, 2000 and 2002 due to severe droughts. During the grazing period of 1982-2012, peak standing crop (PSC) was not measured in 2000 for the three SR treatments, and was measured starting in 1991 for the low SR treatment. Detailed information on the experiment can be found in Derner and Hart (2007), Derner et al. (2008b) and Reeves et al. (2013b).

\subsection{Rangeland-Livestock model description and improvement}

The forage and cattle modules of GPFARM are the simplified version of the Simulating Production and Utilization of Rangeland (SPUR) model (Hanson et al., 1988, 1992). The cattle module was modified to simulate steer herds with average steer forage consumption multiplied by the number of steers to estimate total herd consumption. Model specifications, including functions and equations for both the forage and cattle modules, have been published previously (Andales et al., 2005, 2006). The forage modules calculate daily forage growth and production, which are then used by the cattle modules to assess availability of forage and calculate daily forage intake and animal weight gain based on the demand for forage by animals. Subsequently, the forage modules are updated to incorporate grazing by the cattle module as described below.

In the original model, an index (massEffect) was used to restrict daily forage growth as influenced by grazing. The index for species $\mathrm{j}$ ( massEffect $_{\mathrm{j}}$ ) is calculated based on the following equation

massEffect $_{j}=1-\frac{\text { netPrimProd }_{j}+\text { sForIntake }_{j}}{\text { speciesMax }_{j}}$

where netPrimProd ${ }_{j}$ is net primary production for species $j$ $\left(\mathrm{kg} \mathrm{ha}^{-1}\right)$; speciesMax $_{\mathrm{j}}$ is the user-defined seasonal maximum forage production for species $\mathrm{j}\left(\mathrm{kg} \mathrm{ha}^{-1}\right)$; sForIntake $_{\mathrm{j}}$ is accumulated daily forage intake for forage species group $\mathrm{j}\left(\mathrm{kg} \mathrm{ha}^{-1}\right)$. The massEffect $_{j}$ generally ranges from 1 (netPrimProd $_{j}$ is 0 at the beginning of the season) to near 0 at the end of season. Because the difference in sForIntake $e_{j}$ between SR treatments is very small compared to the value of speciesMax $\mathrm{j}_{\mathrm{j}}$, it has little influence on massEffect $\mathrm{j}_{\mathrm{j}}$ between SR treatments. Based on the Eq. (1) in the original model, less response (decrease) of PSC to the increased SR was simulated, compared to the observed PSC decrease from the low SR treatment $\left(0.20\right.$ steer ha $\left.{ }^{-1}\right)$ to the high SR treatment $\left(0.44\right.$ steer ha $\left.{ }^{-1}\right)$.

To improve the response of PSC to different SR treatments, an index of forage utilization (Eq. (2)), calculated from accumulated daily forage intake and total above ground biomass across the season according to previous studies (Whitson et al., 1976; 
Rickert et al., 2000; Glindemann et al., 2009), was used to represent additional effects of different SR on forage growth and livestock weight gain

Utilization $_{\mathrm{j}}=\frac{\text { sForIntake }_{\mathrm{j}}}{\text { Forage }_{\mathrm{j}}}$

where sForIntake ${ }_{j}$ is defined in Eq. (1); Forage $e_{j}$ is the available forage from total above ground biomass for species $\mathrm{j}\left(\mathrm{kg} \mathrm{ha}^{-1}\right)$. The range of the index is from 0 at the beginning of grazing to 1 if all above ground biomass was grazed. Each forage species or functional group has its own utilization index.

The utilization index reflects grazing pressure, and showed close relationships with harvest efficiency or grazing efficiency as demonstrated by a previous study (Smart et al., 2010). It can be used to quantify the effect of SR on forage production, forage quality and diet digestibility, and cattle weight gain across various weather conditions. For example, the utilization index was used to quantify the effects of forage consumption by animals on subsequent forage growth by reducing the potential carbon fixation and transpiration and increasing soil evaporation due to reduction in leaf area (Rodriguez et al., 1990). It has been used to retard grass growth in a wheat grazing system model (Rodriguez et al. 1990) and to restrict the forage intake due to the decline in quality of diet as utilization increased (Rickert et al., 2000).

In this study, the index of Utilization ${ }_{j}$ was first used to describe

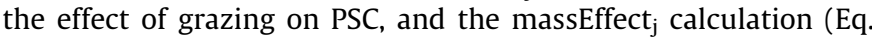
(1)) was revised by adding the index of Utilization ${ }_{j}$ as follows

massEffect $_{\mathrm{j}}=1-\frac{\text { netPrimProd }_{\mathrm{j}}}{\text { speciesMax }_{\mathrm{j}}} \times\left(1+\right.$ Utilization $\left._{\mathrm{j}}\right)$

If Utilization ${ }_{\mathrm{j}}=0$ (no grazing), massEffect $_{\mathrm{j}}$ generally decreases from 1 (netPrimProd $_{j}$ is 0 at the beginning of the season) to near 0 when netPrimProd ${ }_{j}$ is close to NetPrimProd ${ }_{j}$ at the end of season, which is same as Eq. (1). On the other hand, with the increase of Utilization $_{\mathrm{j}}$, the massEffect $\mathrm{j}_{\mathrm{j}}$ will decrease and reduce the forage growth. If massEffect $t_{j}$ is lower than 0 , then massEffect $t_{j}=0$.

The daily forage growth $\left(\Delta W_{\mathrm{j}}, \mathrm{kg} \mathrm{ha}^{-1} \mathrm{~d}^{-1}\right)$ for species $\mathrm{j}$ is calculated from maximum growth rate (maxGrowthRate $\mathrm{j}_{\mathrm{j}} \mathrm{kg} \mathrm{ha}^{-1} \mathrm{~d}^{-1}$ ) and above ground biomass (AboveBio ${ }_{\mathrm{j}}, \mathrm{kg} \mathrm{ha}^{-1}$ ) for species $\mathrm{j}$, and is reduced by environmental fitness factors (EVP, 0-1) and massEffect $_{\mathrm{j}}$ as shown in Eq. (4). The EVP includes temperature and water or nitrogen stress factors calculated by Eq. (5).

$\Delta W_{\mathrm{j}}=$ maxGrowthRate $_{\mathrm{j}} \times$ AboveBio $_{\mathrm{j}} * \mathrm{EVP} *$ massEffect $_{\mathrm{j}}$

$\mathrm{EVP}=\mathrm{ETP} \times \min (\mathrm{EWP}, \mathrm{ENP})$

where ETP is effect of temperature on forage production (0-1) and EWP is effect of water availability on forage production (0-1). The ENP is effect of soil nitrogen stress on forage production $(0-1)$. Hanson et al. (1988) discuss the empirical bases for the functions in detail. The ETP function is an empirical bell-shaped curve with minimum (tempMinG), optimum (tempOptG), and maximum (tempMaxG) temperatures for growth. The EWP is a thresholdresponse curve that is a function of the ratio of actual evapotranspiration (ET) and potential ET, and water stress tolerance (waterStressTol). The ENP is an exponential function curve with forage shoot $\mathrm{N}$ content. Because native rangelands do not have commercial nitrogen fertilizer applied, they were presumed to have stable and low plant-available $\mathrm{N}$ levels. Thus, we did not calibrate the model for $\mathrm{N}$ stress, which is implicitly considered in the calibration of potential growth rate (maxGrowthRate ${ }_{j}$; Andales et al. 2005).

As the utilization index increases (Eq. (2)), the forage quality and diet digestibility will decrease, which will reduce the forage intake and livestock weight gain (Whitson et al., 1976; Glindemann et al., 2009; Rickert et al., 2000). The forage quality response to SR was described by modifying the current expression in GPFARM-Range model with a term involving the Utilization ${ }_{\mathrm{j}}$ index:

QualForage $=\sum_{j=1}^{n}\left(\right.$ forTDN $_{\mathrm{j}} *$ relPref $\left._{\mathrm{j}} *\left(\frac{1}{\text { utilization }_{\mathrm{j}}^{2}+1}\right)\right)$

where QualForage is forage quality for all forage types (functional groups); forTDN $\mathrm{N}_{\mathrm{j}}$ is total digestible nutrients (TDN) for forage type $\mathrm{j}(0-1)$, which is related to the parameters of maximum TDN (forMaxTDN, $\mathrm{kg} \mathrm{kg}^{-1}$ ) and minimum TDN (forMinTDN, $\mathrm{kg} \mathrm{kg}^{-1}$ ) for forage type $\mathrm{j}$; relPref $_{\mathrm{j}}$ is the relative preference for forage type $\mathrm{j}(0-1)$, which is calculated as a function of cattle preference (foragePref) and relative amount of forage type $\mathrm{j} ; n$ is forage type number. We used utilization ${ }_{j}^{2}$ instead of utilization ${ }_{j}$ based on observed differences in steer weight gain (SWG) between low and high SR treatments.

The parameter QualForage can influence total intake TDN (totIntakeTDN, $\mathrm{kg}$ TDN head ${ }^{-1} \mathrm{~d}^{-1}$ ) and diet digestibility (Dig, 0-1), metabolic maintenance requirement (Maint, $\mathrm{kg}$ TDN head ${ }^{-1} \mathrm{~d}^{-1}$ ) (Bourdon, 1983), and daily cattle weight gain ( $\Delta \mathrm{CW}, \mathrm{kg}$ herd ${ }^{-1} \mathrm{~d}^{-1}$ ) as follows

totIntakeTDN $=$ inSup $\times$ QualSup + inForage $\times$ QualForage

Dig $=$ totIntakeTDN $/($ inSup + inForage $)$

Maint $=\frac{\left(0.077 \times+0.0052 *(\text { weight }+ \text { milkProd })^{0.75}\right.}{3.6 \times(0.486+0.243 \times \text { Dig })}$

$\Delta \mathrm{CW}=($ totIntakeTDN-Maint $\times$ efficiency $)$

where inSup and inForage are daily intake of supplement and forage $\left(\mathrm{kg} \mathrm{d}^{-1}\right)$, respectively. QualSup and QualForage are the quality of supplement (0-1, depending on supplement type) and forage $(0-1$, calculated from Eq. (6)), respectively. The inForage is determined by animal weight (weight, $\mathrm{kg}$ herd ${ }^{-1}$ ) and daily target weight gain (gain, kg herd ${ }^{-1} \mathrm{~d}^{-1}$ ) and forage availability. The parameter of

Table 1

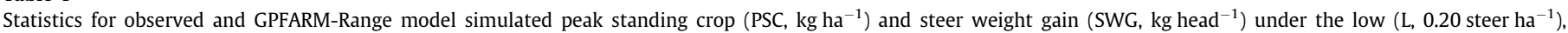
moderate ( $\mathrm{M}, 0.33$ steer ha ${ }^{-1}$, calibration) and high $\left(\mathrm{H}, 0.44\right.$ steer ha $\left.{ }^{-1}\right)$ stocking rate treatments.

\begin{tabular}{|c|c|c|c|c|c|c|c|}
\hline \multirow[t]{2}{*}{ Treatments } & \multirow{2}{*}{$\begin{array}{l}\text { Observed } \\
\text { Mean } \pm \text { SD }\end{array}$} & \multicolumn{3}{|c|}{ Predicted from revised model } & \multicolumn{3}{|c|}{ Predicted from original model } \\
\hline & & Mean \pm SD & RMSE & Pair $t$-test & Mean \pm SD & RMSE & Pair $t$-test \\
\hline \multicolumn{8}{|l|}{ PSC } \\
\hline L (Validation) & $1578 \pm 675$ & $1351 \pm 444$ & 387 & 0.02 & $1376 \pm 500$ & 489 & 0.08 \\
\hline M (Calibration) & $1279 \pm 549$ & $1204 \pm 384$ & 355 & 0.26 & $1353 \pm 450$ & 400 & 0.32 \\
\hline H (Validation) & $1141 \pm 464$ & $1117 \pm 386$ & 358 & 0.76 & $1344 \pm 453$ & 425 & 0.005 \\
\hline \multicolumn{8}{|l|}{ SWG } \\
\hline L (Validation) & $111.4 \pm 22.9$ & $109.1 \pm 14.8$ & 14.2 & 0.26 & $110.8 \pm 15.6$ & 14.7 & 0.84 \\
\hline M (Calibration) & $108.6 \pm 21.2$ & $103.2 \pm 13.8$ & 12.8 & 0.02 & $110.7 \pm 15.6$ & 12.8 & 0.38 \\
\hline $\mathrm{H}$ (Validation) & $97.3 \pm 22.1$ & $94.6 \pm 13.7$ & 13.7 & 0.27 & $110.7 \pm 15.6$ & 21.1 & 0.0002 \\
\hline
\end{tabular}


efficiency is feed utilization efficiency (0-1). Because no supplement was simulated in the current study (inSup $=0$ ), Dig is equal to QualForage (Eqs. (7) and (8)). Maint will increase with increasing body weight and decreasing Dig (Eq. (9)), and cattle weight gain is determined by the difference between totIntake and Maint (Eq. (10)).

\subsection{Model calibration and evaluations}

Daily climate data for Cheyenne, Wyoming were taken from the National Atmospheric and Oceanic Administration (NOAA; http:// www.ncdc.noaa.gov/). These included precipitation (mm), maximum and minimum air temperature $\left({ }^{\circ} \mathrm{C}\right.$ ), solar radiation (Langleys day $\left.^{-1}\right)$, mean wind speed $\left(\mathrm{m} \mathrm{s}^{-1}\right)$, and mean relative humidity (\%). Soil properties of Albinas loam, as the dominant soil at the site, were obtained from the GPFARM soils database. Observed data as described in Section 2.1, including yearly PSC and monthly steer weight during grazing from 1982 to 2012 for moderate SR treatment were used for model calibrations. Observed data from the other two SR treatments (low and high SR treatments) were used for model evaluations. The model was run continuously from 1982 to 2012 for the three SR treatments.

The parameter estimation software, PEST (Doherty, 2010), was used to optimize parameters in the model. One important restriction in PEST optimization is its sensitivity to local minima, the initial parameter values, and the given ranges of the parameters (Gupta et al., 2003). To cope with this, the initial forage growth parameters and cattle parameters were set according to previous studies at the site (Andales et al., 2005, 2006; Qi et al., 2012). According to the previous studies (Andales et al., 2005, 2006), the most sensitive parameters for PSC were maxGrowthRate, tempOptG, degree days to start of senescence (senGDD), and waterStressTol as shown in Eqs. (4) and (5). These parameters were calibrated by matching the simulated with observed yearly PSC from the moderate SR treatment (Appendix A). The cattle preference value for plant functional groups (foragePref) determines desirability as cattle forage, and can influence forage intake and utilization (Eq. (1)) and forage quality (QualForage) as shown in Eq. (4), which was also optimized with observed PSC and steer weight data (Table 1). Because the warm-season grasses and
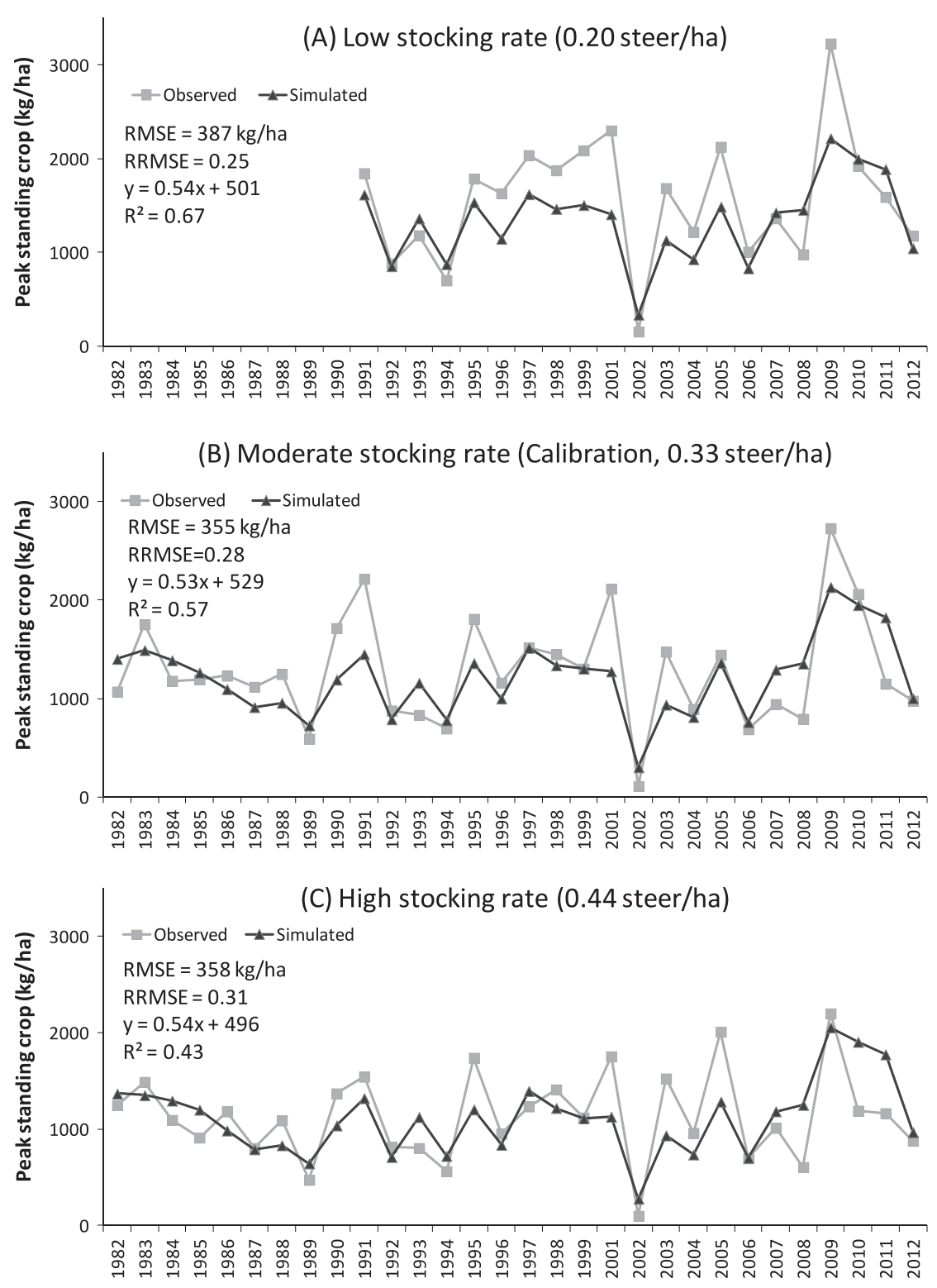

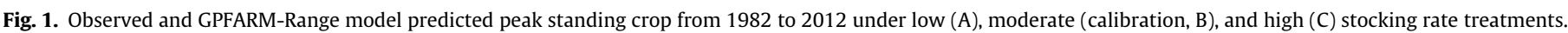


cool-season grasses are the main functional groups in the northern mixed-grass prairie (Manley et al., 1997), above parameters were calibrated only for these two functional groups. The maximum forage production was set at $3250 \mathrm{~kg} \mathrm{ha}^{-1}$ according to the measured maximum PSC value of $3227 \mathrm{~kg} \mathrm{ha}^{-1}$ in 2009 . Other forage parameters were set to their default values suggested in the model or from previous studies (Andales et al., 2005, 2006), and were not calibrated by PEST (Table 1). Other functional groups, such as shrubs and forbs, are rare and default parameters for them were used in the model according to previous study (Andales et al., 2006). Some animal parameters were from a previous study (Andales et al., 2005), such as animal feed requirement and mature weight. Other animal parameters of feed utilization efficiency (efficiency) and target weight gain (gain), influencing on the inForage and weight gain (Eqs. (7)-(10)), were calibrated based on the observed steer weight gain data (Table 1). Initial steer weight at the beginning of grazing was also input for each year based on the observed initial steer weight data before grazing.

To evaluate the model performance, the following statistics were used: root mean squared errors (RMSE; Eq. (11) below), relative RSME (RRMSE, Eq. (12) below) and coefficient of determination $\left(R^{2}\right.$, Eq. (13) below).

$\operatorname{RMSE}=\sqrt{\frac{\sum_{i=1}^{n}\left(O_{i}-P_{i}\right)^{2}}{n}}$

$\mathrm{RRMSE}=\frac{\mathrm{RMSE}}{O_{\text {avg }}}$

$R^{2}=\left\{\frac{\sum_{i=1}^{n}\left(O_{i}-O_{\mathrm{avg}}\right)\left(P_{i}-P_{\mathrm{avg}}\right)}{\left[\sum_{i=1}^{n}\left(O_{i}-O_{\mathrm{avg}}\right)^{2}\right]^{0.5}\left[\sum_{i=1}^{n}\left(P_{i}-P_{\mathrm{avg}}\right)^{2}\right]^{0.5}}\right\}^{2}$

where $P_{i}$ is the $i$ th predicted value, $O_{i}$ is the $i$ th observed value, $P_{\text {avg }}$ and $O_{\text {avg }}$ are the average of observed and simulated values, respectively, and $n$ is the number of data pairs. A paired $t$ test was used for statistical significance testing of the differences in observed and predicted PSC or SWG from 1982 to 2012 among the three SR treatments.

\subsection{Long-term simulations with extended SR above the experiment levels and yearly variability analysis}

Evaluating SR values greater than previously used experimental levels can determine if thresholds exist for influences of SR on forage production and livestock weight gains. Model simulations are needed for these determinations as constraints related to animal health and care protocols can be logistically problematic for experimental evaluations at very high SR. For this paper, following evaluation of the model with high SR, we assessed the forage production and livestock weight gains to SR that were $50 \%$ to $300 \%$ greater than the evaluated experimental high SR (0.44 steer ha ${ }^{-1}$ ). We used 6 SR spanning this range: (1) 50\% higher or 0.66 steer ha ${ }^{-1}$, (2) $100 \%$ higher or 0.88 steer ha $^{-1}$, (3) $150 \%$ higher or 1.10 steer ha $a^{-1}$, (4) $200 \%$ higher or 1.32 steer ha ${ }^{-1}$, (5) $250 \%$ higher or 1.54 steer ha $^{-1}$, and (6) $300 \%$ higher or 1.76 steer ha ${ }^{-1}$ to ascertain if a threshold existed for SR. Based on the long-term simulations, the yearly variability (risk) analysis was carried out for PSC, SWG and economic profit using statistic criteria of coefficient of variation (CV), skewness and the cumulative distribution functions (CDFs). Because the model did not simulate the carrying costs (such as supplement cost, salt, implants and transportation), a simple method was used to estimate the economic profit based on previous studies in the region (Hart et al., 1988; Manley et al., 1997). The purchase price in March and selling price in October for the simulation period (1982-2012) were obtained from National Agricultural Statistics Service (NASS, http://www.nass.usda.gov/Statistics_by_Subject/Economics_and_ Prices/index.asp). Initial steer weight and steer weight gain from the model simulations for these SR levels were used to estimate gross cost and income for each year. Because economic risk analysis was focused on the effect of SR on profits as influence by weather variability, costs of salt, implants, vaccination, trucking and other supplement were set as 30 US dollars per head for the year of 1985 according to Jose et al. (1985). The costs increased year by year due to the inflation in US (http://usinflation.org/us-inflation-rate/) and reached to 64 US dollars in 2012, which is similar to the current carrying cost.

\section{Results and discussion}

\subsection{Model calibrations}

The predicted PSC from our improved model showed similar trends as the observed data from 1982 to 2012 for the moderate
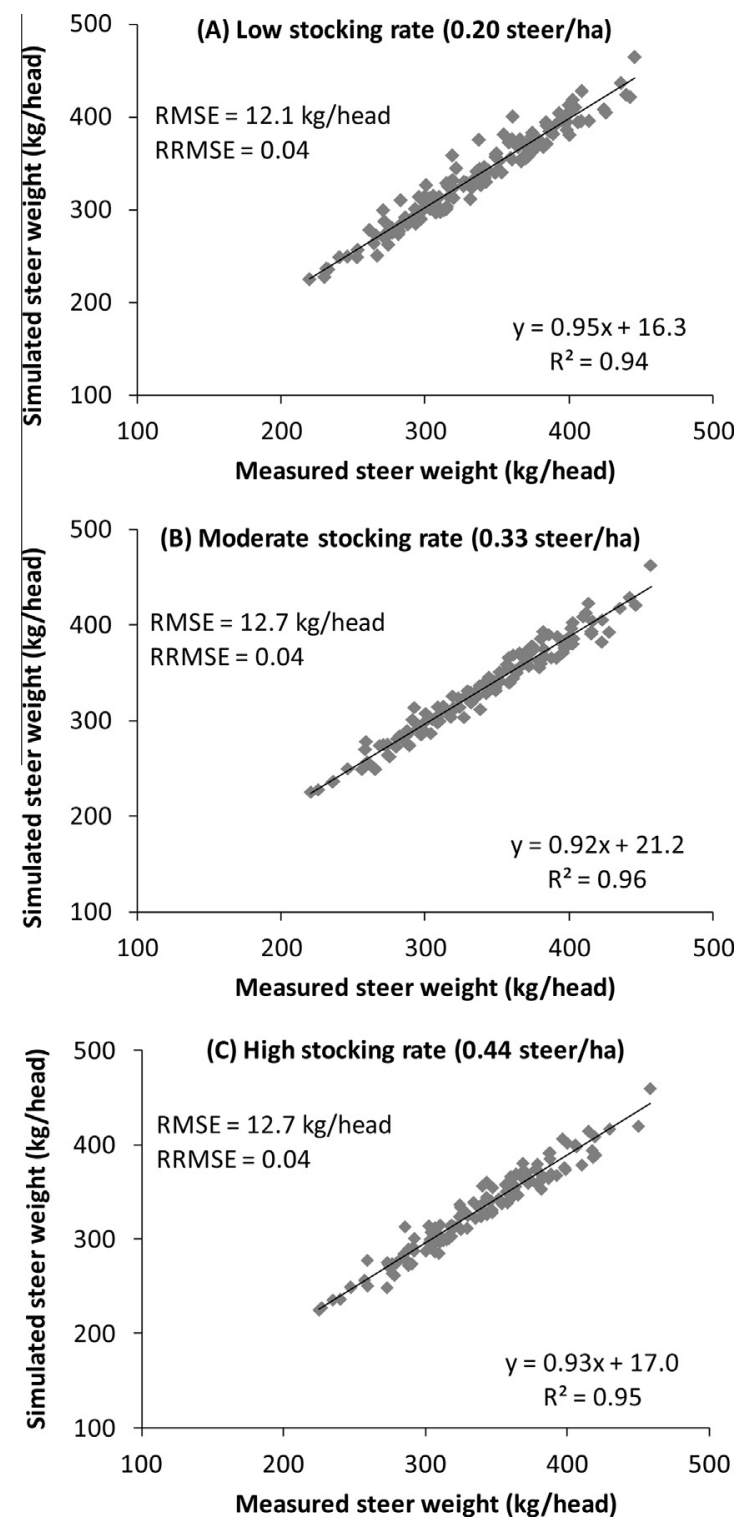

Fig. 2. Comparisons between observed and GPFARM-Range model predicted steer weight under low (A), moderate (B, calibration) and high (C) stocking rate treatments from 1982 to 2012. 
SR (Fig. 1B), with a RMSE value of $355 \mathrm{~kg} \mathrm{ha}^{-1}$, and a RRMSE value of 0.28 . These results were comparable or better than the previous study by Andales et al. (2006). Across the 30 years, the PSC was under-predicted by only $74.6 \mathrm{~kg} \mathrm{ha}^{-1}$ and no significant difference was found between observed and simulated PSC based on a paired $t$-test $(P=0.26)$. The observed PSC showed a higher variation across years than predicted PSC (Table 1 ). The large error in predicted PSC in 2001 was likely due to the severe drought in 2000 (no observed data for 2000 due to the low forage production), especially since Andales et al. (2005) found that the model did not simulate the quick recovery of forage from severe drought.

Predicted steer weight gain (SWG, $\mathrm{kg} \mathrm{head}^{-1}$ ) was close to the observed data (Fig. 2B), with RMSE and RRMSE values of $12.7 \mathrm{~kg}$ head $^{-1}$ and 0.04 , respectively. The model under-predicted SWG by $7.2 \mathrm{~kg} \mathrm{head}^{-1}$, which is consistent with the $74.7 \mathrm{~kg} \mathrm{ha}^{-1}$ under-prediction of PSC. Predicted SWG showed similar trends with observed data from 1982 to 2012 (Fig. 3B), with RMSE value of $13.0 \mathrm{~kg} \mathrm{head} \mathrm{K}^{-1}$, and RRMSE value of 0.12 . Some obvious under-predictions of SWG were probably associated with underpredicted PSC (e.g., 1995 and 2001) or other predicted errors, such as in forage quality and diet digestibility (e.g., 1999, 2004, 2005 and 2007) (Fig. 3B). Averaged from 1982 to 2012, the predicted average yearly SWG was slightly lower by $5.4 \mathrm{~kg} \mathrm{head}^{-1}(5.0 \%)$ than observed data (Table 1, "M" Treatment) that was consistent with the PSC under-predicted by $5.8 \%$. A paired $t$-test showed significant difference between the observed and predicted data $(P=0.02)$, mainly likely due to the under-predictions of SWG in the above-mentioned years. As shown in Table 1, similar predictions of PSC and SWG for the calibrations (moderate SR treatment) were obtained from the original model, and the over-predicted SWG was consistent with the over-predicted PSC.

\subsection{Model evaluations}

Similar to the calibration results, predicted PSC from the revised model showed similar trends as the observed data from 1982 to
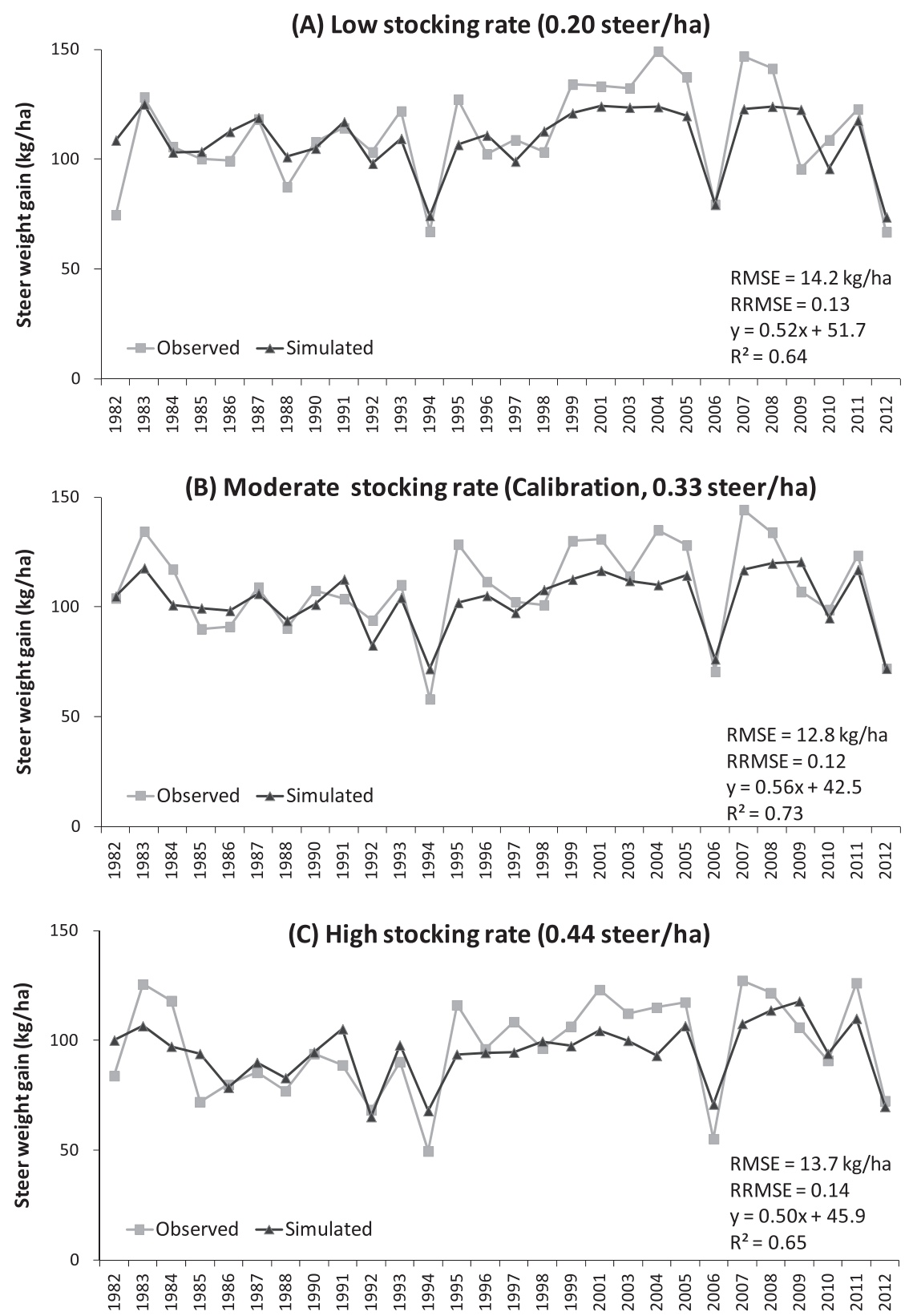

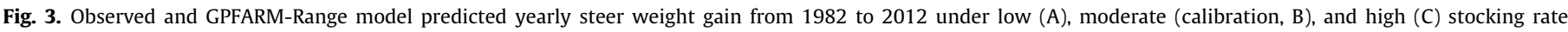
treatments. 
2012 for the low and high SR treatments (Fig. 1A and C). Average PSC was under-predicted by $227 \mathrm{~kg} \mathrm{ha}^{-1}$ from 1991 to 2012 for low SR treatment, and by $24 \mathrm{~kg} \mathrm{ha}^{-1}$ from 1982 to 2012 for high SR treatment (Table 1). There was no significant difference $(P=0.76)$ between predicted and observed PSC from 1982 to 2012 for the high SR treatment based on a paired $t$-test, but a significant difference $(P=0.02)$ between predicted and observed PSC for the low SR treatment.

The revised model predicted SWG was close to the observed data, with similar RMSE and RRMSE values (Fig. 2A and C). The within-season steer weight from 1982 to 2012 was slightly over-predicted by $0.9 \mathrm{~kg} \mathrm{head}^{-1}$ for the low SR treatment, but was under-predicted by $6.7 \mathrm{~kg}$ head $^{-1}$ for the high SR treatment (Fig. 2A and C). The predicted yearly SWG for the low and high SR treatments showed similar results compared to calibrations, with similar RMSE and RRMSE values (Fig. 3A and C vs. Fig. 3B). The paired $t$-test results showed no significant difference between predicted and observed yearly SWG for the low $(P=0.26)$ and high $(P=0.27)$ SR treatments.

We evaluated grazing effect differences between SR treatments (e.g., low vs. moderate (L-M); low vs. high (L-H); high vs. moderate $(\mathrm{M}-\mathrm{H})$ ) for both observed and predicted data on yearly PSC and SWG. As shown in the $x-y$ plane of observed difference vs. predicted difference (Fig. 4A), most of the data for PSC (97\%) were in the1st quadrant or near the origin of coordinate, indicating a good response to these SR treatments. Few data points, such as in 1991 and 2005, were in the 2nd quadrant due to the negative values of these observed differences for $\mathrm{M}-\mathrm{H}$ or $\mathrm{L}-\mathrm{M}$. Most data in the 1st quadrant were below the 1:1 line especially when the observed differences were more than $400 \mathrm{~kg} \mathrm{ha}^{-1}$, suggesting under-predicted PSC difference by the model compared to the observed data. The high observed differences of $1000 \mathrm{~kg} \mathrm{ha}^{-1}$
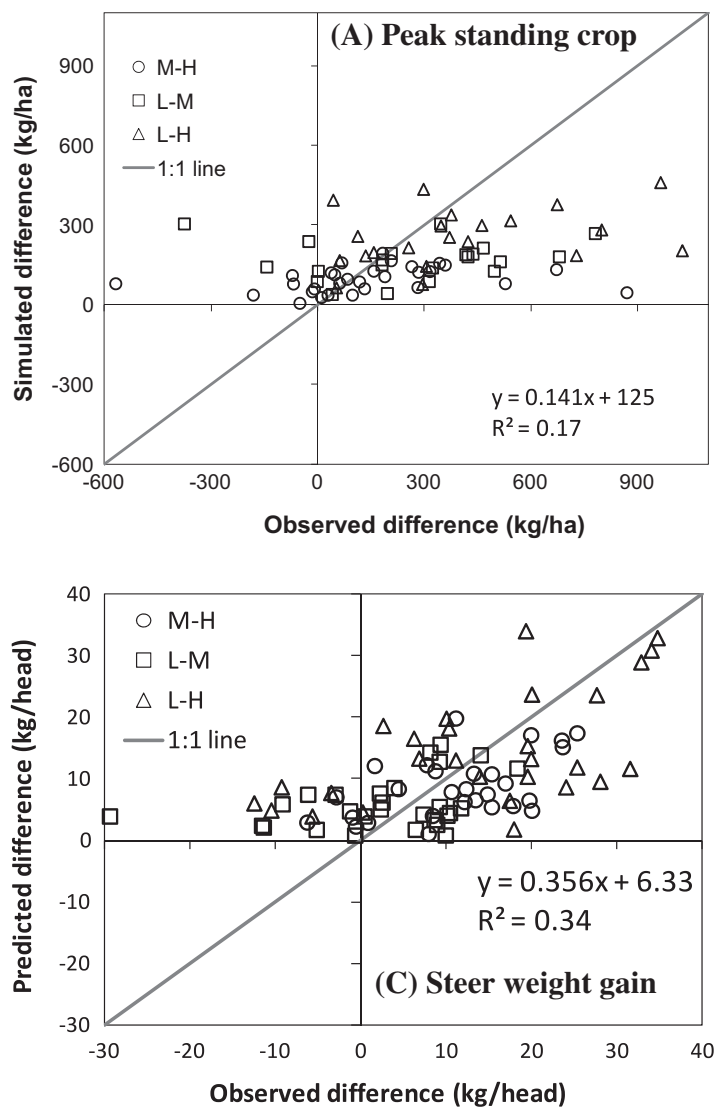

(mean value is $437.8 \mathrm{~kg} \mathrm{ha}^{-1}$ ) between low and high SR treatments in 1999 and 2009 are attributable to the greater abundance of highly productive cool-season grasses $\left(C_{3}\right.$ perennial grass) in the low compared to the high SR treatment (Derner et al., 2008a).

For the observed difference vs. predicted difference of yearly SWG (Fig. 4C), most of the data were in the 1 st quadrant or near the origin of coordinate, and along the 1:1 line, except for some under-predicted differences for L-H and L-M. This result suggested that the model predicted well differences among treatments in terms of yearly SWG. The obvious negative value $\left(-29.3 \mathrm{~kg} \mathrm{head}^{-1}\right)$ for observed difference in SWG in 1982 between light and moderate SR treatments was not simulated. Significant differences $(P<0.001)$ in yearly SWG was found between these SR treatments for both observed and predicted data based on the paired $t$-test.

The improved responses of the revised model (predicted PSC and SWG) to SR (Fig. 4A and C) were associated with the increased utilization index, decreased massEffect values, and reduced forage quality as SR increased (e.g., from 0.20 to 0.44 steer ha $^{-1}$ as shown in Appendix B). In contrast, the original model showed significant difference from measured data for the high SR treatments $(P=0.005$ and 0.0002 , respectively) (Table 1$)$. The corresponding RMSE values were also higher than for the revised model predictions (Table 1). The original model predicted the difference in PSC (Fig. 4B) or SWG (Fig. 4D) between these SR treatments to be nearly 0 or in the fourth quadrant, suggesting less response of predicted PSC or SWG to the increase of SR. On the other hand, significant difference $(P<0.001)$ in PSC (Fig. 4A) or SWG (Fig. 4C) between these SR treatments was found for both observed and the revised model predicted data based on the paired $t$-test.

The calibration and evaluation results showed that the revised model produced better PSC and SWG responses to different SR levels across seasons compared to the original model, and can be used
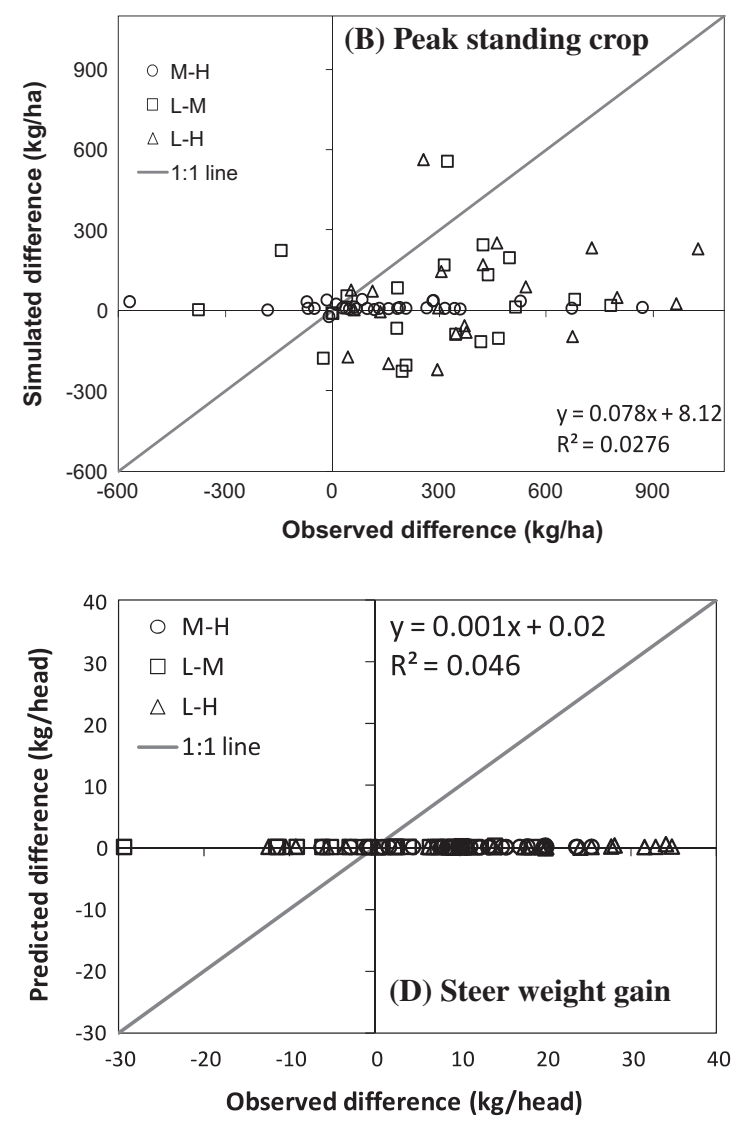

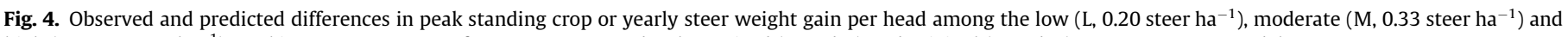
high $\left(\mathrm{H}, 0.44\right.$ steer ha $\left.{ }^{-1}\right)$ stocking rate treatments from 1982 to 2012 by the revised (A and C) and original (B and D) GPFARM-Range model. 
to quantify the SR and seasonal weather variability effects on PSC and SWG.

\subsection{Quantifying grazing and weather effects on PSC and SWG}

\subsubsection{Long-term SR effects on PSC and SWG and yearly variability}

The predicted long-term (1982-2012) average PSC showed a decrease with increased SR (PSC $=926.07 \mathrm{SR}^{-0.213}, R^{2}=0.99$; Fig. 5A), which was consistent with field experiment data. The predicted total forage intake (TotIntake, $\mathrm{kg} \mathrm{ha}^{-1}$, Fig. 5A) and total intake TDN (TotTDN, $\mathrm{kg} \mathrm{TDN} \mathrm{ha}^{-1}$, Fig. 5B) increased quadratically with SR (TotIntke $=-208.65 S R^{2}+1146.5 S R-56.09, R^{2}=1$; Tot$\mathrm{TDN}=-138.72 \mathrm{~S} R^{2}+558.72 \mathrm{~S} R+2.45, R^{2}=1$; Fig. 5). The diminishing increase of TotIntake or TotTDN at high SR levels was mainly due to both decreased PSC (Fig. 5A) and forage quality as SR and Utilization index increased (Eqs. (2), (6), (7), and Appendix B). The simulated metabolic maintenance requirement per area (Maint, kg TDN ha ${ }^{-1}$ ), however, increased linearly with increased SR (Maint $=295.76 S R+1.52, R^{2}=1$; Fig. 5B), because the Maint per head (Eq. (9)) was relatively stable due to the decreased steer weight and diet digestibility with increased SR (Eqs. (6)-(8), and Appendix B). The quadratic response of SWG to SR showed a decline in the net return of SWG with the increase of SR, which was determined by the difference between TotTDN and Maint (Eq. (10)). The quadratic increase of TotTDN and linear increase of Maint resulted in quadratic increase of TotTDN-Maint as SR increased, where maximum TotTDN-Maint values at about 0.88 steer ha $^{-1}$ produced maximum SWG (Fig. 5B).

As shown in Fig. 5C, the yearly variability (coefficient of variation, CV) in TotTDN-Maint increased exponentially from 0.21 to 3.81 as SR increased from 0.20 to 1.76 steer ha ${ }^{-1}$, which was consistent with the increase of CV from 0.17 to 3.25 for SWG. The CV values for PSC (0.29-0.37), Maint (0.21-0.20) and TotTDN (0.18-0.28) changed less with SR compared to the CV change of SWG. This result indicated that the quadratic response of TotTDN and linear response of Maint to SR resulted in high yearly variability of SWG at high SR levels, which explained the higher sensitivity of SWG to seasonal weather variations under higher SR levels (Reeves et al., 2013b, 2014).

Fig. 5A and B showed threshold response of SWG per area to SR (about 0.88 steer ha ${ }^{-1}$ ) and PSC (about $939 \mathrm{~kg} \mathrm{ha}^{-1}$ ) in the region. This biophysical optimum SR resulted in high harvest efficiency of 0.84 (total forage intake/PSC defined by Smart et al. (2010), Fig. 5A), and high yearly variability in SWG (CV values between 0.34 and 0.50 ) due to the weather variations (Fig. 5C). Recent field experimental studies have shown significant influence of spring rainfall amount (April-June) on PSC and SWG in the region, and can help ranchers make better SR decisions (Derner and Hart, 2007; Derner et al., 2008a; Wiles et al., 2011; Reeves et al. 2013a,b, 2014). We also found that the biophysical optimum SR with maximum SWG per area for each year from 1982 to 2012 showed a positive increase with spring rainfall $(S R=0.0027$ Rainfall +0.5346 , $\left.R^{2}=0.24, P=0.005\right)$ or PSC (SR $=0.0009 P S C+0.1743, R^{2}=0.51$, $P=0.0001$ ).

The responses of PSC and SWG to SR under dry (below $80 \%$ average spring rainfall), normal (80-120\% average spring rainfall), and wet (above $120 \%$ spring rainfall) weather conditions were further compared to select better SR for these different weather conditions (Fig. 6). As SR increased, the SWG per area increased more for the wet seasons than for the dry seasons due to the different PSC levels under the different weather conditions (Fig. 6). The biophysical optimum SR increased from about 0.88 steer ha $^{-1}$ for the dry or normal seasons (Fig. 6A and B) to about 1.10 steer ha $^{-1}$ for the wet seasons (Fig. 6C). The corresponding daily SWG per head was $0.36 \mathrm{~kg} \mathrm{head}^{-1} \mathrm{day}^{-1}$ (dry seasons), $0.48 \mathrm{~kg} \mathrm{head}^{-1} \mathrm{day}^{-1}$ (normal seasons), and $0.60 \mathrm{~kg} \mathrm{head}^{-1} \mathrm{day}^{-1}$ (wet seasons), which
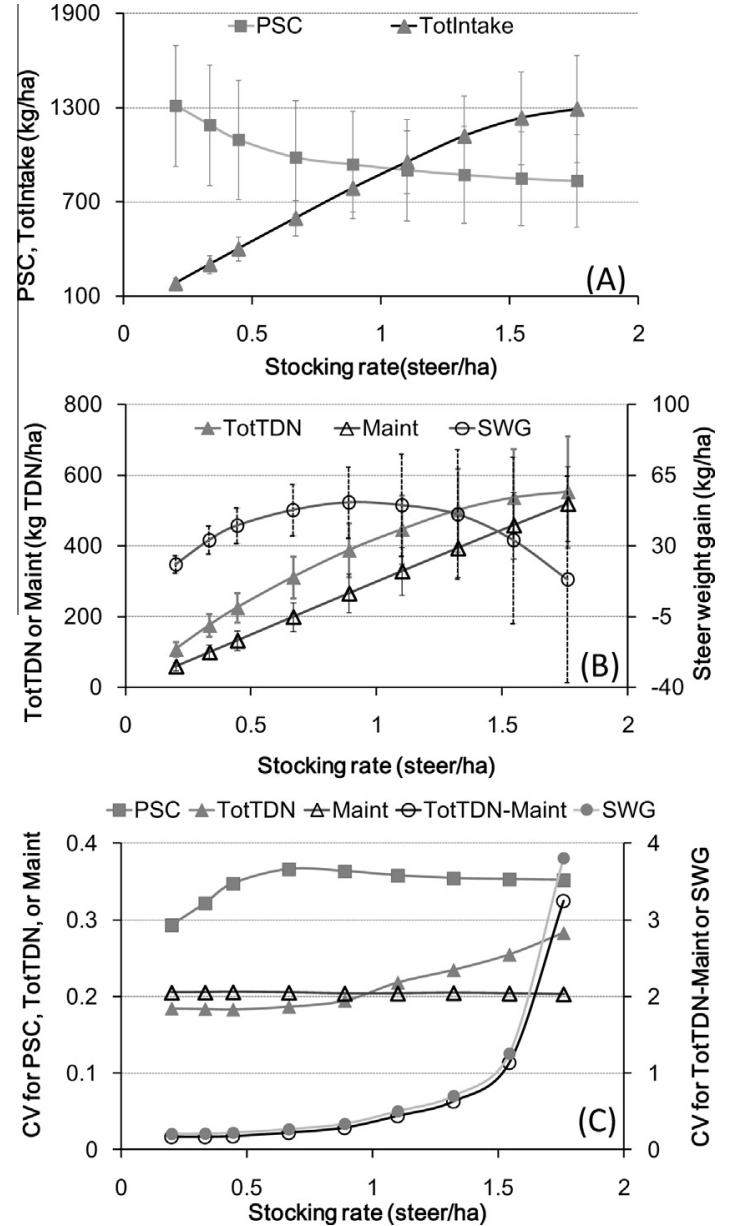

Fig. 5. GPFARM-Range model predicted long-term (1982-2012) average peak standing crop (PSC), total forage intake (TotIntake), total intake digestible nutrients (TotTDN), metabolic maintenance requirement (Maint) and steer weight gain (SWG), and the coefficient of variation (CV) for PSC, TotTDN, Maint, TotTDN-Maint and SWG across seasons as influenced by the stocking rates (SR) from 0.20 steer ha $^{-1}$ to 1.76 steer ha $^{-1}$.

were much lower than the values reported for moderate SR $\left(0.82 \mathrm{~kg} \mathrm{head}^{-1} \mathrm{day}^{-1}\right.$, Hart et al. 1988 , and $0.83 \mathrm{~kg} \mathrm{head}^{-1}$ day $^{-1}$ Manley et al. 1997).

Compared to the lowest SR of 0.20 steer ha ${ }^{-1}$, the PSC at the biophysical optimum SR levels were reduced by $29 \%, 33 \%$ and $27 \%$, with high harvest efficiency values of $0.98,0.96$ and 0.86 for the dry, normal and wet weather conditions, respectively (Fig. 6). The reduced PSC with increased harvest efficiency for the biophysical optimum SR likely affects ecosystem functions negatively, such as reducing soil carbon storage and increasing the risk of soil degradation as discussed by Derner and Hart (2007). The high yearly variability of SWG (CV $=0.47$ for dry seasons; $C V=0.22$ for normal seasons; $\mathrm{CV}=0.33$ for wet seasons) at these biophysical optimum SR levels also suggests elevated risks in obtaining these maximum SWG per area (Fig. 6). When considering the above results, the practical SR should be much lower than the biophysical optimum SR levels. Galt et al. (2000) proposed a harvest efficiency of $25 \%$ for moderate SR level, which can be obtained at SR levels between 0.22 and 0.33 steer ha ${ }^{-1}$ for the dry or normal weather seasons, or between 0.33 and 0.44 steer ha $^{-1}$ for the wet weather seasons (Fig. 6). The above reduced SR levels resulted in higher marginal SWG, and can be more practical for ranchers to obtain high SWG per head and PSC with low yearly variability and avoid land degradations.

Based on the economic profits analysis (Fig. 6), the financially optimal SR with highest profits was considerably lower than the 
biophysical optimum SR levels, and increased from about 0.33 steer ha $^{-1}$ for the dry seasons to about 0.44 steer ha $^{-1}$ for the wet seasons, with net returns increasing from $\$ 13.19 \mathrm{ha}^{-1}$ to $\$ 35.34 \mathrm{ha}^{-1}$. The low financially-optimum SR was mainly due to the faster rate of increase in cost relative to SWG, as SR increased (White and McGinty, 1997; Kemp et al., 2013). These financial optimum SR levels were $37.5 \%, 50 \%$, and $40 \%$ of the biophysical optimum SR levels, for the dry, normal and wet seasons, respectively. Above results were close to the previous studies with experimental data in the region (Hart et al., 1988; Manley et al., 1997). The corresponding SWG per area was reduced by $32 \%$ (dry seasons), 20\% (normal seasons) and 31\% (wet seasons) from the SWG at biophysical optimum SR, respectively, but the yearly variability (CV) for SWG was reduced by 30\% (dry seasons), 64\% (normal seasons) and 75\% (wet seasons) (Fig. 6). The average daily weight gain was $0.71 \mathrm{~kg} \mathrm{head}^{-1} \mathrm{day}^{-1}$ for dry season, $0.82 \mathrm{~kg} \mathrm{head}^{-1} \mathrm{day}^{-1}$ for normal season or $0.90 \mathrm{~kg} \mathrm{head}^{-1} \mathrm{day}^{-1}$ for wet season, with forage harvest efficiency of $0.32,0.29$ or 0.31 , respectively. Such reduced SR levels can benefit the land ecosystem and may also produce higher quality products and possible higher economic profits as discussed by Kemp et al. (2013).

\subsubsection{Seasonal PSC and SWG response to SR and risk analysis}

The CDFs were developed as decision tools for evaluating the risks associated with different SR levels (Fig. 7). As SR increased, the simulated PSC at lower SR levels showed a first-degree stochastic dominance (FDSD) to the simulated PSC at higher SR level across these years (Fig. 7A). The CV and skewness values for the simulated PSC increased with SR from 0.20 to 0.88 steer ha ${ }^{-1}$ and were stable at further higher SR levels (Table 2). The lowest SR resulted in both highest PSC and lowest yearly variability (lowest
$\mathrm{CV})$. The Skewness values near zero $(-0.08)$ for the simulated PSC at 0.20 steer ha ${ }^{-1}$ indicated a normal distribution of PSC across these years. The higher skewness values for PSC at SR levels higher than 0.44 suggest a higher probability (risk) of obtaining lower PSC than average PSC across years.

The FDSD analysis for SWG per area (Fig. 7B) showed that the predicted SWG with higher SR unambiguously dominated the simulated SWG with lower SR when SR increased from 0.20 to 0.44 steer ha ${ }^{-1}$. The predicted SWG with SR of 0.66 steer ha $^{-1}$ also dominated the predicted SWG with SR of 0.20 or 0.33 steer ha ${ }^{-1}$, but showed higher yearly variability (CV) than the lower SR levels (Table 2). No other FDSD was found in the simulated SWG among these SR levels. As SR increased from 0.66 to 0.88 steer ha $^{-1}$, the predicted SWG increased but with higher yearly variability, and further increases in SR levels resulted in decreased predicted SWG with higher yearly variability (Table 2 ).

The CDFs for the net return from 1982 to 2012 showed an increase in economic profits with increased SR from 0.22 to 0.44 steer ha $^{-1}$ across most years (Fig. 7B). A decrease in profits occurred with increased SR levels of 0.44 or 0.88 steer ha $^{-1}$ and negative profits were obtained at SR levels between 1.10 and 1.76 steer ha ${ }^{-1}$ due to reduced SWG and increased costs (Table 2). The high SR also resulted in high yearly variability of the profits compared with these lower SR levels between 0.22 and 0.44 steer $\mathrm{ha}^{-1}$ (Table 2). The economic profits with SR level between 0.33 and 0.44 steer ha ${ }^{-1}$ showed a second-degree stochastic dominance (SDSD) to the profits at SR between 0.66 and 0.88 steer ha ${ }^{-1}$, which may be preferred by risk-averse ranchers.

These CDFs can help ranchers determine expected net return with a certain probability. For example, to obtain a higher PSC level than the $1218 \mathrm{~kg} \mathrm{ha}^{-1}$ for the moderate SR (Derner and Hart, 2007),
(A) Dry seasons
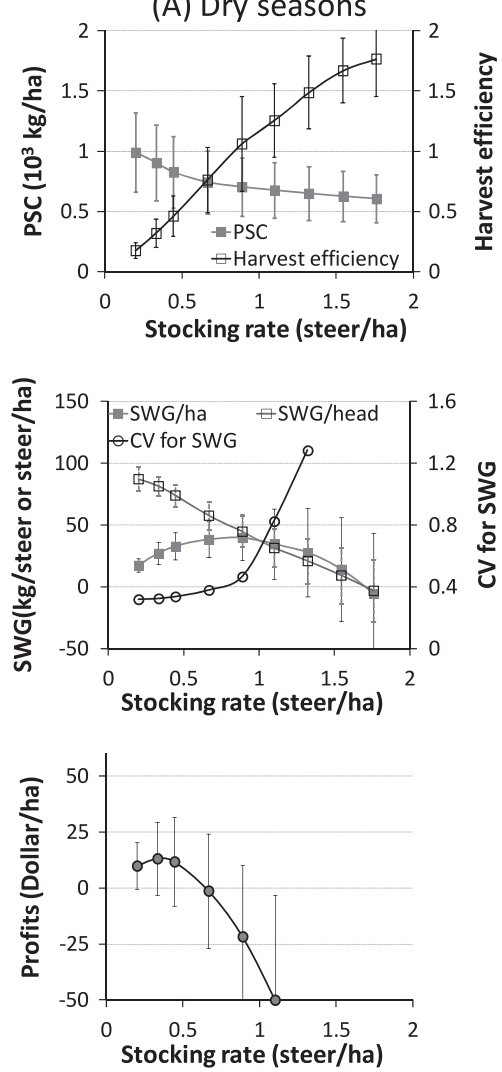

(B) Normal seasons
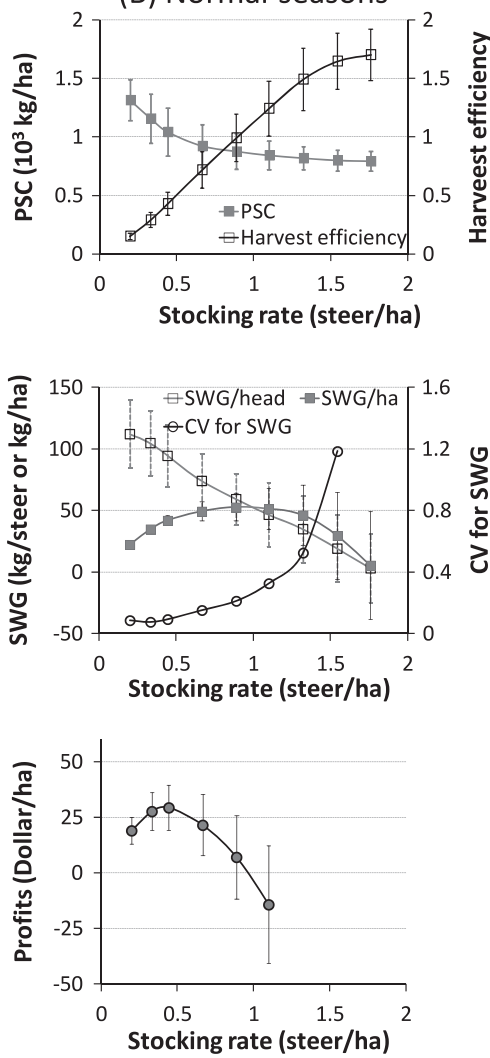

(C) Wet seasons
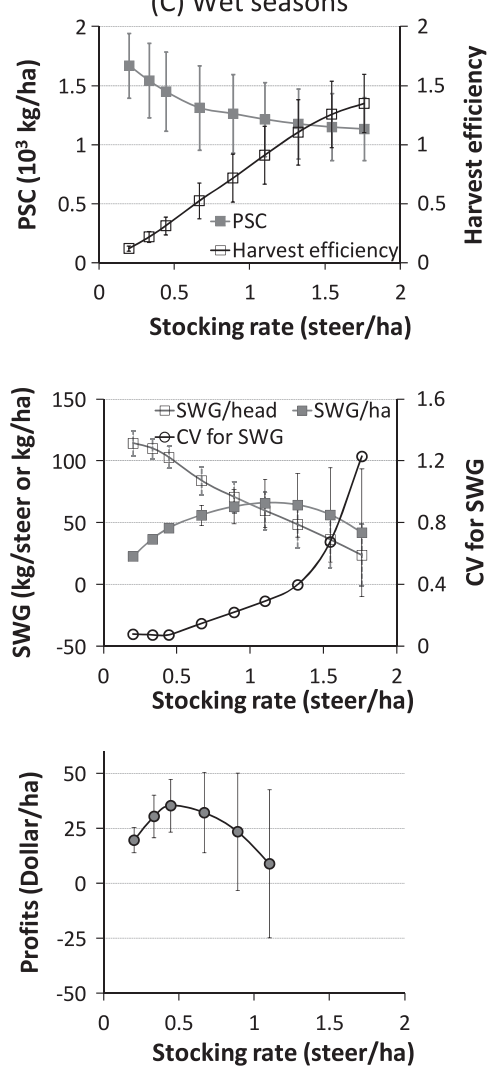

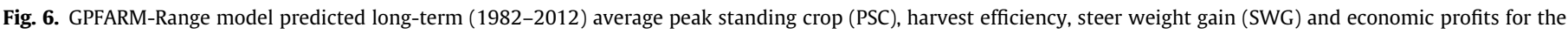

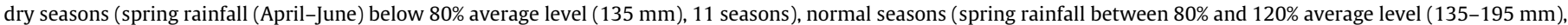

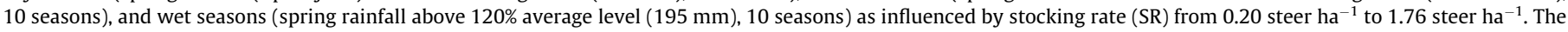
coefficient of variation (CV) values for SWG and negative net return for the high SR are presented in Table 2. 

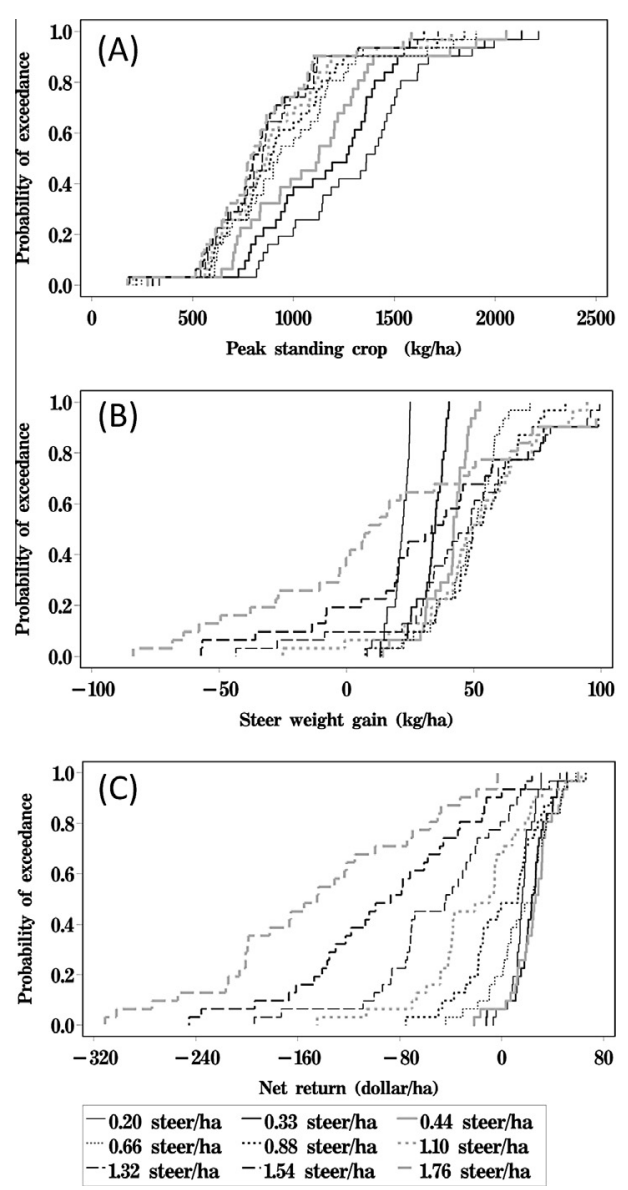

Fig. 7. Cumulative distribution functions of GPFARM-Range model predicted peak standing crop (PSC, $\mathrm{kg} \mathrm{ha}^{-1}$ ) (A) and yearly steer weight gain (B, $\mathrm{kg} \mathrm{ha}^{-1}$ ), and economic net return (dollar ha ${ }^{-1}$ ) for the 9 stocking rates from 1982 to 2012.

a cumulative probability of $50 \%$ to $70 \%$ occurred for the 3 experimentally-evaluated treatments (L: 0.20 steer ha $^{-1}$; M: 0.33 steer ha ${ }^{-1} ; \mathrm{H}: 0.44$ steer ha $^{-1}$ ), and a cumulative probability from $10 \%$ to $40 \%$ was found for SR $>0.44$ steer ha ${ }^{-1}$ (Fig. 7 A). Similarly, SWG was below $50 \mathrm{~kg} \mathrm{ha}^{-1} 100 \%$ all years for the 3 experimentally-evaluated treatments (Fig. 7B), but resulted in positive profits at more than $90 \%$ of the time (Fig. 7C). Higher SR from 0.66 steer ha $^{-1}$ to 1.10 steer ha $^{-1}$ increased SWG to $>50 \mathrm{~kg} \mathrm{ha}^{-1}$ with a cumulative probability of about $50 \%$ of the time, but resulted in negative profits at $23 \%\left(S R=0.66\right.$ steer ha $\left.^{-1}\right), 45 \%$ $\left(\mathrm{SR}=0.88\right.$ steer $^{-1} \mathrm{a}^{-1}$ ) and $68 \%\left(\mathrm{SR}=1.10\right.$ steer ha $\left.^{-1}\right)$ of the time. Further increases in SR decreased the probability $(<50 \%)$ of obtaining higher than $50 \mathrm{~kg} \mathrm{ha}^{-1} \mathrm{SWG}$, and induced a probability above
$80 \%$ of obtaining negative profits across the years. These results can help ranchers choose SR levels to lower risks of negative economic profits and rangeland degradation associated with yearly weather variations.

\section{Conclusions and remarks}

In the revised GPFARM-range model, grazing effects on forage growth and cattle weight gain were improved by incorporating an index of utilization based on previous studies. The improved model predicted the effects of SR on PSC and SWG adequately across years (root mean square errors from 355 to $387 \mathrm{~kg} \mathrm{ha}^{-1}$ for PSC and from 12.8 to $14.2 \mathrm{~kg} \mathrm{head}^{-1}$ for SWG), and can be used to predict forage production and cattle weight gain under different SR across various weather conditions on the northern mixed-grass prairie.

Long-term simulations extended the previous results on seasonal weather effects on PSC and SWG under experimental SR levels to coupled effects of seasonal weather variability and grazing management on PSC and SWG for a wider range of SR levels. The long-term simulation results showed that the biophysical optimum SR increased from 0.88 steer ha ${ }^{-1}$ for the dry or normal seasons to 1.10 steer ha ${ }^{-1}$ for the wet seasons, and the financial optimum SR increased from 0.33 steer ha ${ }^{-1}$ for the dry or normal seasons to 0.44 steer ha $^{-1}$ for the wet seasons. The biophysical optimum SR produced the highest SWG $\left(\mathrm{kg} \mathrm{head}^{-1}\right)$ with high yearly variability and resulted in low PSC with high harvest efficiency (possible land degradation), along with lower or negative economic profits. The financially optimum SR with relatively lower SWG per area produced highest economic profits with low yearly variability and higher PSC with lower harvest efficiency, and may benefit the stability of vegetation composition. At the financially optimum SR, higher SWG per head (daily SWG per head) occurred and resulted in an earlier date to reach selling weights. The CDFs risk analysis of the simulated PSC, SWG, and economic profits for these SR levels provide useful information for ranchers when selecting yearly SR, as they consider economic and environmental returns, as well as yearly variability associated with weather variations.

To further improve simulations of SWG by the GPFARM-range model, some additional variables could be included. One is the direct influence of weather variables and forage quality/quantity on SWG through changes in steer grazing behavior and energy use efficiency. For example, hot weather decreases steer grazing and forage intake (Trudell and White, 1981). The second is accounting for the effect of weather variables on both forage growth and forage quality (Craine et al., 2009). The underpredicted SWG in this study could be partly due to errors in predicted forage quality or diet digestibility, where cattle may have access to higher quality forage and result in high SWG in the field

Table 2

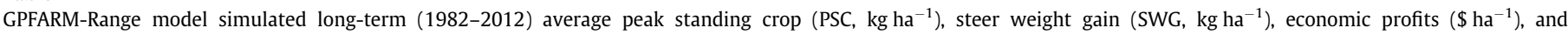
corresponding coefficient of variance (CV, standard deviation/average) and skewness across the years for the 9 stocking rate (SR) treatments.

\begin{tabular}{|c|c|c|c|c|c|c|c|c|c|}
\hline Item & $\mathrm{SR}=0.2$ & $S R=0.33$ & $S R=0.44$ & $S R=0.66$ & $S R=0.88$ & $S R=1.10$ & $\mathrm{SR}=1.32$ & $S R=1.54$ & $S R=1.76$ \\
\hline \multicolumn{10}{|l|}{ PSC } \\
\hline Mean & 1314 & 1192 & 1097 & 984 & 939 & 904 & 874 & 850 & 836 \\
\hline $\mathrm{CV}$ & 0.29 & 0.32 & 0.35 & 0.37 & 0.36 & 0.36 & 0.35 & 0.35 & 0.35 \\
\hline Skewness & -0.08 & 0.28 & 0.52 & 0.76 & 0.81 & 0.82 & 0.81 & 0.78 & 0.72 \\
\hline \multicolumn{10}{|l|}{ SWG } \\
\hline Mean & 20.8 & 32.7 & 40 & 47.7 & 51.5 & 50.1 & 45.5 & 32.8 & 13.4 \\
\hline $\mathrm{CV}$ & 0.21 & 0.21 & 0.22 & 0.27 & 0.34 & 0.5 & 0.71 & 1.26 & 3.81 \\
\hline Skewness & -1.47 & -1.53 & -1.38 & -0.78 & -0.37 & -0.80 & -0.80 & -0.39 & 0.01 \\
\hline \multicolumn{10}{|l|}{ Profits } \\
\hline Mean & 16.0 & 23.5 & 25.1 & 16.9 & 2.2 & -20.2 & -49.0 & -91.6 & -144.7 \\
\hline $\mathrm{CV}$ & 0.55 & 0.60 & 0.70 & 1.43 & 14.63 & -2.19 & -1.11 & -0.76 & -0.59 \\
\hline Skewness & -0.56 & -0.64 & -0.68 & -0.58 & -0.29 & -0.64 & -0.67 & -0.36 & -0.08 \\
\hline
\end{tabular}


Appendix A1

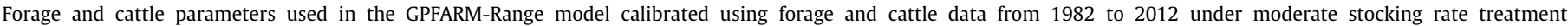
(0.33 steer ha $\left.{ }^{-1}\right)$.

\begin{tabular}{|c|c|c|c|c|c|}
\hline \multirow[t]{2}{*}{ Plant parameters } & \multirow[t]{2}{*}{ Definition } & \multicolumn{2}{|c|}{ Warm season grasses } & \multicolumn{2}{|c|}{ Cool season grasses } \\
\hline & & Final & Initial and range & Final & Initial and range \\
\hline \multicolumn{6}{|l|}{ Calibrated } \\
\hline maxGrowthRate & Maximum relative growth rate & 0.24 & $0.22(0.20-0.26)$ & 0.23 & $0.20(0.18-0.24)$ \\
\hline senGDD & Growing degree days until senescence begins & 1600 & $1400(1300-1700)$ & 1000 & $1100(900-1300)$ \\
\hline tempOptG & Optimum temperature for growth & 31 & $30(27-33)$ & 18 & $20(16-23)$ \\
\hline waterStress & Water stress tolerance & 0.18 & $0.20(0.15-0.25)$ & 0.15 & $0.15(0.10-0.20)$ \\
\hline propPop & Proportion of population from each functional group & 0.39 & - & 0.53 & - \\
\hline \multicolumn{6}{|l|}{ Default } \\
\hline matureGDD & GDDs to maturity & 1500 & - & 2200 & - \\
\hline respRate & Respiration rate & 0.03 & - & 0.03 & - \\
\hline tempMinG & Minimum temperature for growth & 5 & - & 0 & - \\
\hline tempMaxG & Maximum temperature for growth & 45 & - & 36 & - \\
\hline forMaxTDN & Maximum TDN in each functional group & 0.64 & - & 0.67 & - \\
\hline forMinTDN & Minimum TDN in each functional group & 0.54 & - & 0.57 & - \\
\hline Cattle parameters & Definition & Final & Initial and range & & \\
\hline Efficiency & Feed utilization efficiency & 0.44 & $0.50(0.40-0.60)$ & & \\
\hline Gain & Target weight gain & 0.94 & $0.90(0.75-0.95)$ & & \\
\hline
\end{tabular}

“-“Indicates parameters without calibration which were taken from model default value or previous studies in the region (Andales et al., 2005).

experiment. Inter-annual dynamics of the model merit improvement as the model did not capture carryover effects following a poor forage production year, nor the ability of this resilient rangeland ecosystem to recover from extreme weather (such as the 2000 drought).

\section{Appendix A}

See Appendix A1.

\section{Appendix B}

Comparisons of utilization index (Eq. (2), A), MassEffect index (Eq. (3), B) and forage quality index (Eq. (4), C) from 2006 to 2008 between low $\left(0.20\right.$ steer ha $\left.^{-1}\right)$ and high $\left(0.44\right.$ steer ha $\left.^{-1}\right)$ stocking rate treatments, as calculated by the improved GPFARMRange model.
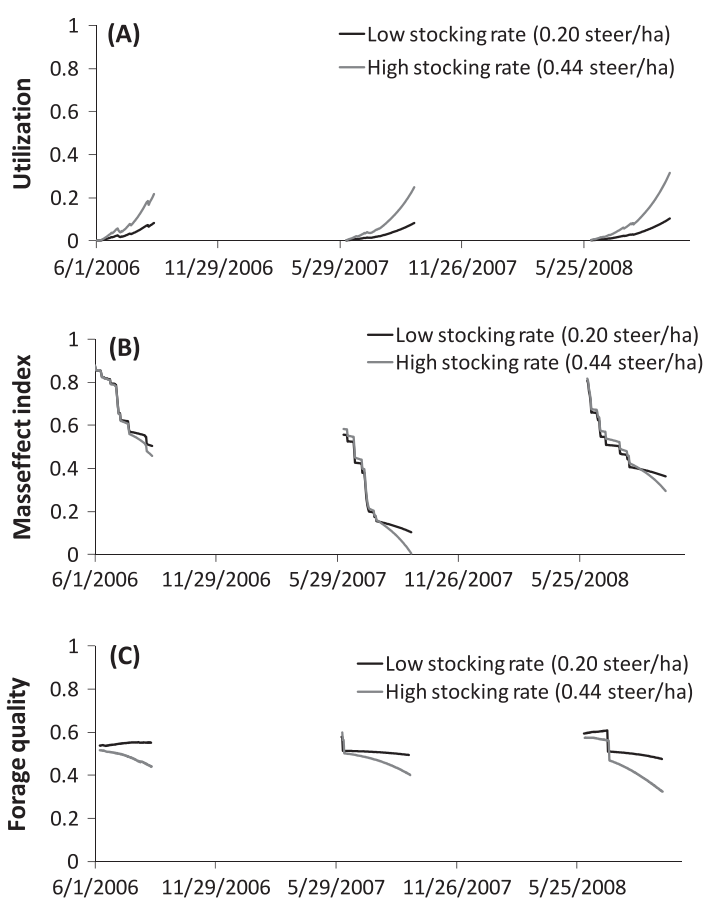

\section{References}

Andales, A.A., Derner, J.D., Bartling, P.N.S., Ahuja, L.R., Dunn, G.H., Hart, R.H., Hanson, J.D., 2005. Evaluation of GPFARM for simulation of forage production and cow calf weights. Rangeland Ecol. Manage. 58, 247-255.

Andales, A.A., Derner, J.D., Ahuja, L.R., Hart, R.H., 2006. Strategic and tactical prediction of forage production in northern mixed-grass prairie. Rangeland Ecol. Manage. 59, 576-584.

Berntsen, J., Petersen, B.M., Jacobsen, B.H., Olesen, J.E., Hutchings, N.J., 2003. Evaluating nitrogen taxation scenarios using the dynamic whole farm simulation model FASSET. Agric. Syst. 76, 817-839.

Biondini, M.E., Patton, B.D., Nyren, P.E., 1998. Grazing intensity and ecosystem processes in a northern mixed-grass prairie. Ecol. Appl. 8, 469-479.

Bourdon, R.M., 1983. Simulated Effects of Genotype and Management on beef Production Efficiency. Ph.D. Dissertation. Colorado State Univ., Fort Collins CO.

Craine, J.M., Towne, E.G., Joern, A., Hamilton, R.G., 2009. Consequences of climate variability for the performance of bison in tallgrass prairie. Glob. Change Biol. $15,772-779$.

Derner, J.D., Hart, R.H., 2007. Grazing-induced modifications to peak standing crop in northern mixed-grass prairie. Rangeland Ecol. Manage. 60, 270-276.

Derner, J.D., Hess, B.W., Olson, R.A., Schuman, G.E., 2008a. Functional group and species responses to precipitation in three semi-arid rangeland ecosystems. Arid Lands Res. Manage. 22, 81-92.

Derner, J.D., Hart, R.H., Smith, M.A., Waggoner, J.W., 2008b. Long-term cattle gain responses to stocking rate and grazing systems in northern mixed-grass prairie. Livest. Sci. 117, 60-69.

Doherty, J., 2010. PEST, Model-independent parameter estimation-User manual (5th ed., with slight additions): Brisbane, Australia, Watermark Numerical Computing.

Freer, M., Moore, A.D., Donnelly, J.R., 1997. GRAZPLAN: decision support systems for Australian grazing enterprises. II. The animal biology model for feed intake, production and reproduction and the GrazFeed DSS. Agric. Syst. 54, 77-126.

Galt, D., Molinar, F., Navarro, J., Joseph, J., Holechek, J., 2000. Grazing capacity and stocking rate. Rangelands 22 (6), 7-11.

Gillen, R.L., Sims, P.L., 2006. Stocking rate and weather impacts on sand sagebrush and grasses: a 20-year record. Rangeland Ecol. Manage. 59 (2), 145-152.

Glindemann, T., Wang, C., Tas, B.M., Schiborra, A., Gierus, M., Taube, F., Susenbeth, A., 2009. Impact of grazing intensity on herbage intake, composition, and digestibility and on live weight gain of sheep on the Inner Mongolian steppe. Livest. Sci. 124 (1), 142-147.

Gupta, H.V., Sorooshian, S., Hogue, T.S., Boyle, D.P., 2003. Advances in automatic calibration of watershed models. In: Duan, Q., Gupta, H., Sorooshian, S. Rousseau, A., Turcotte, R. (Eds.), Water Science and Application Series 6, pp. 197-211.

Hanson, J.D., Skiles, J.W., Parton, W.J., 1988. A multispecies model for rangeland plant communities. Ecol. Model. 44, 89-123.

Hanson, J.D., Baker, B.B., Bourdon, R.M., 1992. SPUR2 Documentation and user guide. GPSR Technical Report No. 1. USDA-ARS, Fort Collins, Colorado.

Hart, R.H., Samuel, M.J., Test, P.S., Smith, M.A., 1988. Cattle, vegetation, and economic responses to grazing systems and grazing pressure. J. Range Manage. 41, 282-286.

Johnson, I.R., 2013. DairyMod and the SGS Pasture Model: A Mathematical Description of the Biophysical Model Structure. IMJ Consultants, Dorrigo, NSW, Australia.

Jose, D., Bltney, L., Duey, D., Miss, P., Robb, J., Sheffield, L.L., 1985. Estimated crop and livestock production costs. Nebraska Coop. Ext. Serv. Ext. Circ., 84-872. 
Kemp, D.R., Guodong, H., Xiangyang, H., Michalk, D.L., Fujiang, H., Jianping, W., Yingjun, Z., 2013. Innovative grassland management systems for environmental and livelihood benefits. Proc. Nat. Acad. Sci. 110 (21), 8369-8374.

Manley, W.A., Hart, R.H., Samuel, M.J., Smith, M.A., Waggoner, J.W., Manley, J.T., 1997. Vegetation, cattle, and economic responses to grazing strategies and pressures. J. Range Manage. 50, 638-646.

Patton, B.D., Dong, X., Nyren, P.E., Nyren, A., 2007. Effects of grazing intensity, precipitation, and temperature on forage production. Rangeland Ecol. Manage. 60 (6), 656-665.

Qi, Z., Bartling, P.N., Ahuja, L.R., Derner, J.D., Dunn, G.H., Ma, L., 2012. Development and evaluation of the carbon-nitrogen cycle module for the GPFARM-Range model. Comput. Electron. Agric. 83, 1-10.

Reeves, J.L., Derner, J.D., Sanderson, M.A., Petersen, M.K., Vermeire, L.T., Hendrickson, J.R., Kronberg, S.L., 2013a. Seasonal temperature and precipitation effects on cow-calf production in northern mixed-grass prairie. Livest. Sci. 155, 355-363.

Reeves, J., Derner, J., Sanderson, M., Petersen, M., Vermeire, L., Hendrickson, J., Kronberg, S., 2013b. Temperature and precipitation affect steer weight gains differentially by stocking rate in northern mixed-grass prairie. Rangeland Ecol. Manage. 66 (4), 438-444.

Reeves, J., Derner, J., Sanderson, M., Hendrickson, J., Kronberg, S., Petersen, M., Vermeire, L., 2014. Seasonal weather influences on yearling beef steer production in C3-dominated Northern Great Plains rangeland. Agric. Ecosyst. Environ. 183, 110-117.

Rickert, K.G., Stuth, J.W., McKeon, G.M., 2000. Modelling pasture and animal production. In: Mannetje, L., Jones, R.M. (Eds.), Field and Laboratory Methods for Grassland and Animal Production Research. CAB Publishing, Wallingford, UK, pp. 29-66.
Rodriguez, A., Trapp, J.N., Walker, O.L., Bernardo, D.J., 1990. A wheat grazing systems model for the US southern plains: Part I - Model description and performance. Agric. Syst. 33 (1), 41-59.

Smart, A.J., Derner, J.D., Hendrickson, J.R., Gillen, R.L., Dunn, B.H., Mousel, E.M. Olson, K.C., 2010. Effects of grazing pressure on efficiency of grazing on North American Great Plains rangelands. Rangeland Ecol. Manage. 63 (4), 397-406.

Snow, V.O., Rotz, C.A., Moore, A.D., Martin-Clouaire, R., Johnson, I.R., Hutchings, N.J. Eckard, R.J., 2014. The challenges-and some solutions-to process-based modelling of grazed agricultural systems. Environ. Model. Softw. <http:// dx.doi.org/10.1016/j.envsoft.2014.03.009>.

Stevenson, A., Baumgartner, R.E., Schuman. G.E., 1984. High Plains Grasslands Research Station detailed soil survey. Laramie, WY: US Department of Agriculture, Agricultural Research Service, Wyoming Agricultural Experiment Station, US Department of Agriculture, Soil Conservation Service. USDA Publication 1-84/1C/3.62, pp. 100.

Trudell, J., White, R.G., 1981. The effect of forage structure and availability on food intake, biting rate, bite size and daily eating time of reindeer. J. Appl. Ecol. 18 63-81.

White, L.D., McGinty, A., 1997. Stocking Rate Decisions. Texas A\&M Univ. Agr. Ext. Serv. Publ., pp. 13-5036.

Whitson, R.E., Parks, D.L., Herd, D.B., 1976. Effects of forage quality restrictions on optimal production systems determined by linear programming. Southern J. Agric. Econom. 8 (2), 1-4.

Wiles, L.J., Dunn, G., Printz, J., Patton, B., Nyren, A., 2011. Spring precipitation as a predictor for peak standing crop of mixed-grass prairie. Rangeland Ecol Manage. 64 (2), 215-222. 